Proceedings

\title{
Climatic Suitability for Haplodrassus rufipes in a Mediterranean Area: Linking a Predaceous Species to the Olive Grove ${ }^{+}$
}

\author{
Jacinto Benhadi-Marín ${ }^{1}$, José Alberto Pereira ${ }^{1}$ and Sónia A. P. Santos 2,* \\ 1 Centro de Investigação de Montanha (CIMO), ESA, Instituto Politécnico de Bragança, Campus de Santa \\ Apolónia, 5300-253 Bragança, Portugal; jbenma@ipb.pt (J.B.-M.); jpereira@ipb.pt (J.A.P.) \\ 2 CIQuiBio, Barreiro School of Technology, Polytechnic Institute of Setúbal, Lavradio, Portugal \\ * Correspondence: sonia.santos@estbarreiro.ips.pt; Tel.: +351-212-064-660 \\ + Presented at the 1st International Electronic Conference on Plant Science, 1-15 December 2020; Available \\ online: https://iecps2020.sciforum.net/.
}

Published: 30 November 2020

\begin{abstract}
The use of natural enemies against crop pests has been promoted during the last decades. Efficient pest limitation relies on the overlap of the predator and the pest in time and space. In Portugal, the cultivation of the olive tree (Olea europaea L.) represents a key economic and cultural activity. Previous works highlighted the ground hunter spider Haplodrassus rufipes as a promising natural enemy against the olive fruit fly Bactrocera oleae, the main pest of the olive tree in northeastern Portugal. The objectives of this work were to approximate the distribution of H. rufipes throughout the whole Iberian Peninsula using its climatic suitability and compare it with the distribution of $O$. europaea. For this, a maximum entropy model at a $1 \mathrm{~km}$ resolution was developed. The distribution of $O$. europaea was visualized using a chorological map. The most contributing bioclimatic variable to the maxent model was the mean diurnal range. The distribution of $O$. europaea fairly overlapped the highest values of the bioclimatic suitability of $H$. rufipes throughout the Iberian Peninsula.
\end{abstract}

Keywords: maxent; species distribution; natural enemies; Iberian Peninsula

\section{Introduction}

The olive grove agroecosystem is a relevant activity with a social and economic impact in Mediterranean areas threatened by pressures of the socioeconomic current situation [1]. Although this ecosystem is usually considered somehow stable due to the stability of the environment, the tolerance of pest damage, a complex network of insects inhabiting the crop, and abundant natural enemies [1], the crop is not free of threats such as the attack of important pests. Among these, the monophagous frugivorous pest Bactrocera oleae (Rossi, 1790) (Diptera: Tephritidae), the olive fly, is one of the most pernicious causing significant losses every year [2]. On the other hand, among the natural enemies of the olive fly, the spiders raised interest as potential predators that could play a role in pest limitation e.g., [3].

In the light of the diversity and ubiquity of spiders, efforts must be made in targeting those species or guilds (e.g., groups of species using the same hunting strategy) with the potential to successfully prey on the olive fly. In this context, the first condition to meet is that the species coincides in space with the crop range. To assess this relationship at a broad geographical scale, the use of species distribution models (SDM) represents a useful approach. 
Species distribution models allow linking occurrence data to environmental drivers through measures of the relationship between species and the environment [4]. The resulting maps represent habitat suitability values or probability values depending on the underlying occurrence data see [5].

Haplodrassus rufipes (Lucas, 1846) (Araneae: Gnaphosidae) is a medium-sized active ground hunting spider (prosoma length $3.5 \mathrm{~mm}$ ) [6]. Both sexes have been observed preying on adults and pupae of B. oleae in laboratory [7]. Although it has been observed inhabiting the olive crop in Portugal [7], the number of occurrence records reported for the Iberian Peninsula is still low. In this work, we aimed at developing an SDM able to predict the habitat suitability of $H$. rufipes throughout the Iberian Peninsula and compare it with the range of O. europaea.

\section{Experiments}

The model was developed using $\mathrm{R}$ [8] using the machine-learning method maxent. This modelling procedure uses the maximum entropy to approximate the distribution of a species based on presence-only data [9]. We used the R implementation of maxent of \{dismo\} package [10].

The bioclimatic variables used were obtained from the WorldClim database [11], a gridded climate database derived from monthly temperature and rainfall. The bioclimatic data was used at 0.5 min spatial resolution $\left(\sim 1 \mathrm{~km}^{2}\right)$ ( Table 1$)$.

Table 1. Description of bioclimatic variables provided by the WorldClim database.

\begin{tabular}{cc}
\hline Code in Database & Bioclimatic Variable \\
\hline bio1 & Annual mean temperature \\
bio2 & Mean diurnal range (mean of monthly $($ max temp - min temp)) \\
bio3 & Isothermality (bio2/bio7) $(\times 100)$ \\
bio4 & Temperature seasonality (standard deviation $\times 100)$ \\
bio5 & Max temperature of warmest month \\
bio6 & Min temperature of coldest month \\
bio7 & Temperature annual range (bio5-bio6) \\
bio8 & Mean temperature of wettest quarter \\
bio9 & Mean temperature of driest quarter \\
bio10 & Mean temperature of warmest quarter \\
bio11 & Mean temperature of coldest quarter \\
bio12 & Annual precipitation \\
bio13 & Precipitation of wettest month \\
bio14 & Precipitation of driest month \\
bio15 & Precipitation seasonality (coefficient of variation) \\
bio16 & Precipitation of wettest quarter \\
bio17 & Precipitation of driest quarter \\
bio18 & Precipitation of warmest quarter \\
bio19 & Precipitation of coldest quarter \\
\hline
\end{tabular}

No selection of variables was done a priori see [12]. However; the model was refitted using the three most contributing drivers after a first tunning procedure. The tuning of the maxent model followed Muscarella et al. (2014) [13] towards a balance of goodness-of-fit with model complexity and evaluation of models with spatially independent data. The "checkerboard1" method for partitioning occurrence data was used to build a pool of 40 models corresponding to five combinations of feature classes (linear, quadratic, product, threshold, and hinge) and eight regularisation multipliers $(\beta)(0.5,1,1.5,2,2.5,3,3.5$, and 4$)$. The selected optimal model was the one 
that achieved the lowest AIC (Akaike Information Criterion). For the optimal model, the AUC (area under the curve) was calculated and used as a measure of the predictive potential of the model [14]. The occurrence data was obtained from the GBIF database $[15,16]$ and the chorological map of O. europaea from Caudullo, et al. (2017) [17].

\section{Results}

The model that best performed was the one combining the linear, quadratic, hinge, and product features (LQHP) with a regularisation multiplier $\beta=2$ (Table A1). The model was developed using 1000 background points, 24 presence records for training, and 7 for testing. This model gave an AIC $=978.37$ and resulted in three parameters. The AUC was $0.69 \pm 0.07(\mathrm{SD})$. The percent contribution of the three bioclimatic drivers used was $71.10,23.90$, and $5.0 \%$ for the precipitation of the driest month, the temperature annual range, and mean diurnal range, respectively.

The most suitable area for H.rufipes was found to correspond to the main Mediterranean climate areas throughout the Iberian Peninsula and mostly overlapped with the distribution of O. europaea (Figure 1). The response curve obtained for the most contributing bioclimatic variable, the precipitation of the driest month, decreased as the amount of precipitation increased (Figure 2).

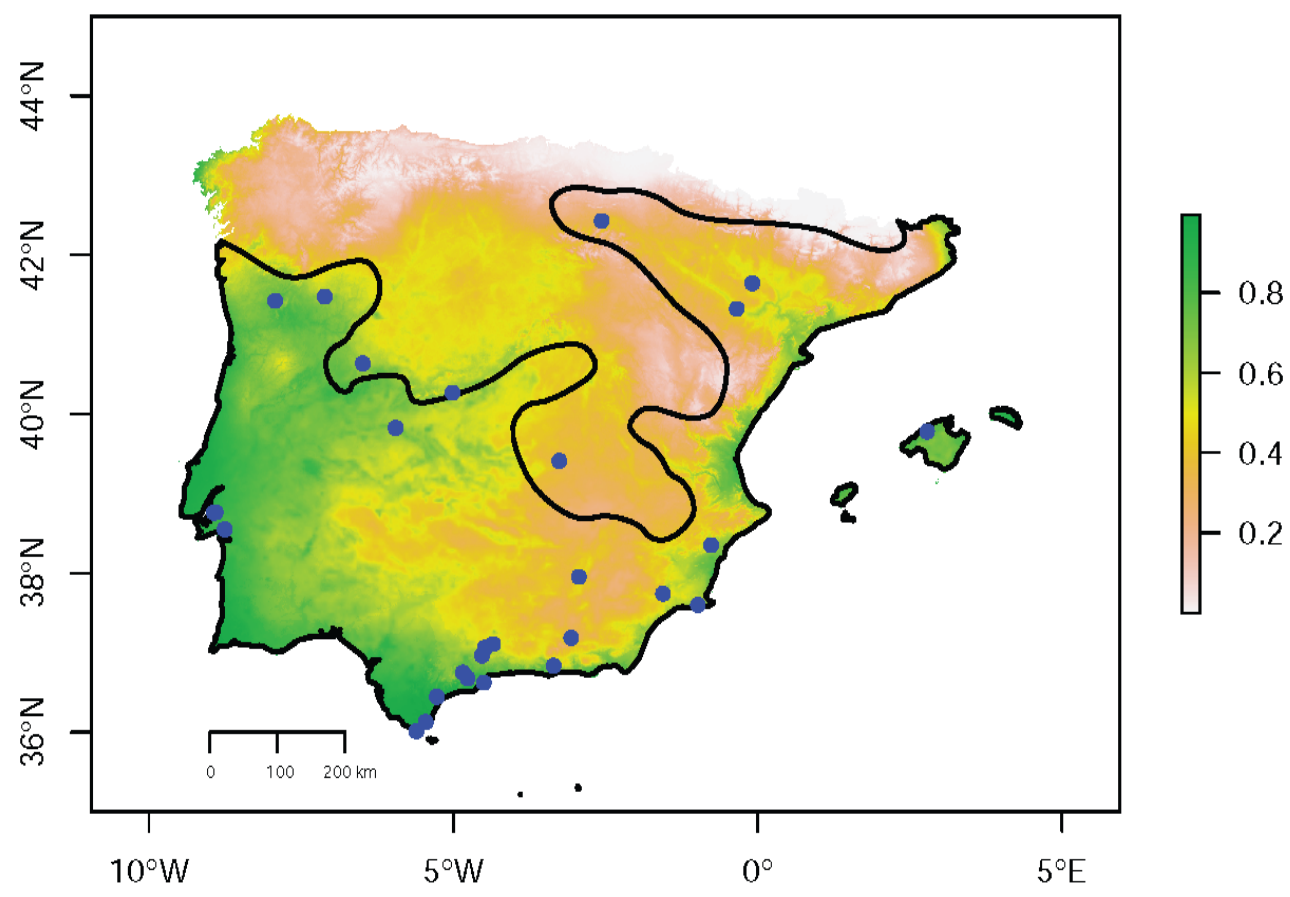

Figure 1. Biolclimatic suitability map for Haplodrassus rufipes in the Iberian Peninsula. Blue dots represent occurrence records. Black line represents the contour of the chorlogical map of Olea europaea. 


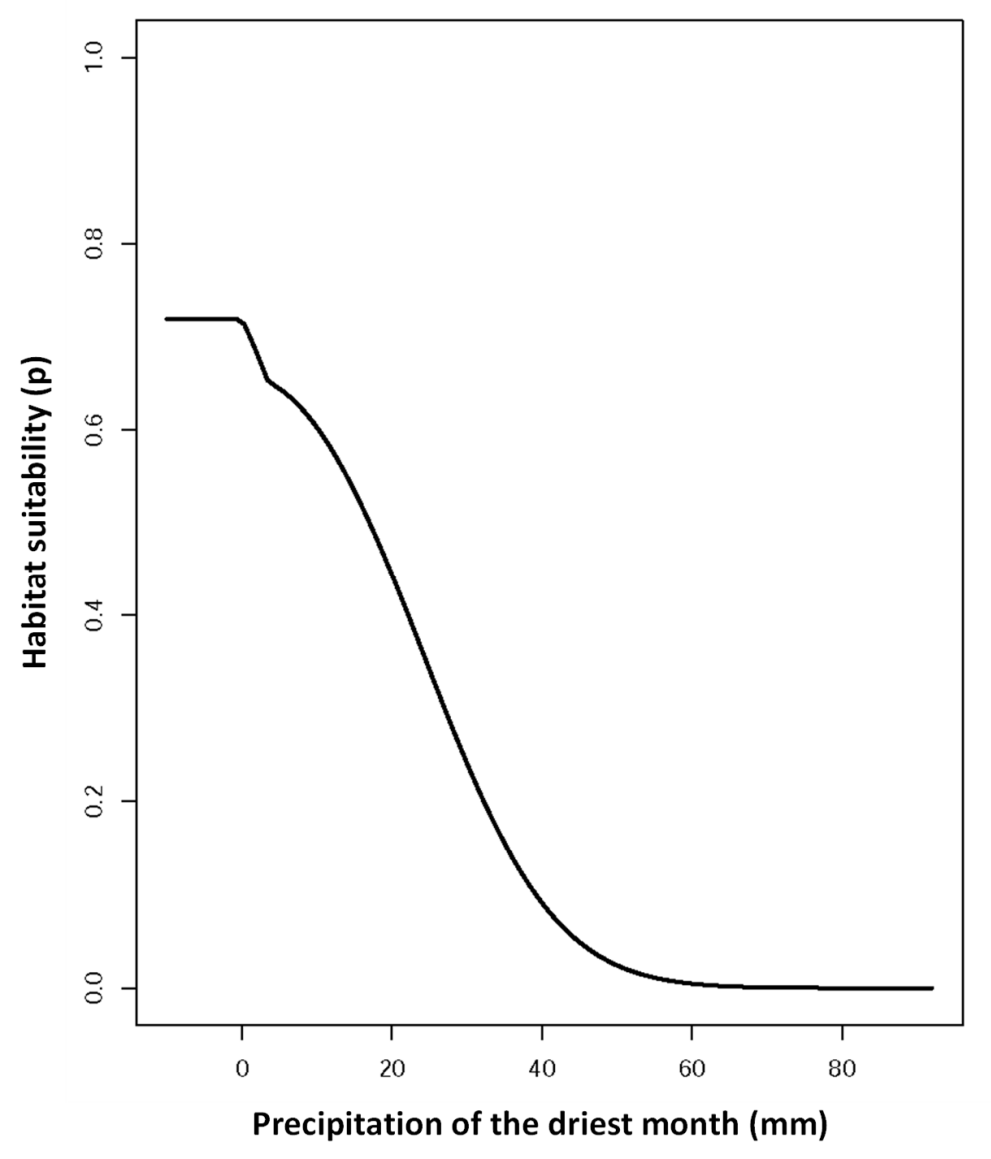

Figure 2. Response curve (habitat suitability) of Haplodrassus rufipes according to the precipitation of the driest month in the Iberian Peninsula.

\section{Dicussion}

Species distribution models proved to be useful to evaluate the predicted range of potential natural enemies. Comparing this range with the geographical distribution of a crop can help to assess the feasibility of considering different species as potential natural enemies. In this work, The high amount of overlap of the distribution of the spider and the crop suggest that further studies on the role of $H$. rufipes as a potential natural enemy in the olive grove agroecosystem are worthy. The amount of contribution of the precipitation of the driest month to the model suggests that this driver may significantly affect the life-cycle of $H$. rufipes. The strong decreasing pattern of habitat suitability as the precipitation increases suggests that this could be a species adapted to dry environments such as the mediterranean ecosystem, especially during summer. This agrees with the adaptations of the olive grove to grow under dry conditions [18].

\section{Conclusions}

Research on the life-cycle and functional response of H. rufipes on B. oleae may allow parametrizing individual-based models and predict the rate of predation in the field thus allowing to evaluate the eficiency of the spider as agent of biological control.

Author Contributions: S.A.P.S., J.A.P. and J.B.-M. conceived the idea, J.B.-M. developed the model and prepared the figures, all authors contributed to writing and reviewing the paper. All authors have read and 
agreed to the published version of the manuscript. All authors have read and agreed to the published version of the manuscript.

Acknowledgments: The authors are grateful to the Foundation for Science and Technology (FCT, Portugal), for financial support through the project "Gestão dos serviços de ecossistema no olival utilizando modelos espaciais avançados-OLIVESIM" PTDC/ASP-PLA/30003/2017.

Conflicts of Interest: The authors declare no conflict of interest.

\section{Appendix A}

Table A1. Outputs of the maxent model tuning for Haplodrassus rufipes. Bold text indicates the selected model with the lowest AIC. RM: Regularization multiplier.

\begin{tabular}{ccccc}
\hline Model & Features & RM & AIC & Parameters \\
\hline 1 & L & 0.5 & 982.3185 & 3 \\
2 & L & 1 & 982.4030 & 3 \\
3 & L & 1.5 & 982.5269 & 3 \\
4 & L & 2 & 982.6856 & 3 \\
5 & L & 2.5 & 982.8816 & 3 \\
6 & L & 3 & 983.1131 & 3 \\
7 & L & 3.5 & 983.3792 & 3 \\
8 & L & 4 & 983.6834 & 3 \\
9 & LQ & 0.5 & 978.8699 & 3 \\
10 & LQ & 1 & 978.9590 & 3 \\
11 & LQ & 1.5 & 979.1044 & 3 \\
12 & LQ & 2 & 979.3069 & 3 \\
13 & LQ & 2.5 & 979.5627 & 3 \\
14 & LQ & 3 & 979.8737 & 3 \\
15 & LQ & 3.5 & 980.2352 & 3 \\
16 & LQ & 4 & 980.6515 & 3 \\
17 & LQH & 0.5 & 991.0409 & 10 \\
18 & LQH & 1 & 985.1734 & 7 \\
19 & LQH & 1.5 & 986.7045 & 6 \\
20 & LQH & 2 & 979.4320 & 3 \\
21 & LQH & 2.5 & 979.6956 & 3 \\
22 & LQH & 3 & 980.0127 & 3 \\
23 & LQH & 3.5 & 980.3777 & 3 \\
24 & LQH & 4 & 980.7951 & 3 \\
25 & LQHP & 0.5 & 992.5499 & 10 \\
26 & LQHP & 1 & 981.4068 & 5 \\
27 & LQHP & 1.5 & 982.4808 & 5 \\
28 & LQHP & $\mathbf{2}$ & $\mathbf{9 7 8 . 3 7 0 2}$ & 3 \\
29 & LQHP & 2.5 & 982.2892 & 4 \\
30 & LQHP & 3 & 981.1815 & 3 \\
31 & LQHP & 3.5 & 982.8461 & 3 \\
32 & LQHP & 4 & 984.7757 & 3 \\
33 & LQHPT & 0.5 & 1016.0185 & 17 \\
34 & LQHPT & 1 & 984.6857 & 7 \\
35 & LQHPT & 1.5 & 987.4957 & 7
\end{tabular}




\begin{tabular}{ccccc}
36 & LQHPT & 2 & 979.7848 & 4 \\
37 & LQHPT & 2.5 & 980.8471 & 4 \\
38 & LQHPT & 3 & 982.1643 & 4 \\
39 & LQHPT & 3.5 & 983.7439 & 4 \\
40 & LQHPT & 4 & 985.5982 & 4 \\
\hline
\end{tabular}

\section{References}

1. Loumou, A.; Giourga, C. Olive groves: The life and identity of the Mediterranean. Agric. Hum. Values 2003, 20, 87-95.

2. Malheiro, R.; Casal, S.; Baptista, P.; Pereira, J.A. A review of Bactrocera oleae (Rossi) impact in olive products: From the tree to the table. Trends Food Sci. Technol. 2015, 44, 226-242.

3. Picchi, M.S.; Bocci, G.; Petacchi, R.; Entling, M.H.; Effects of local and landscape factors on spiders and olive fruit flies. Agric. Ecosyst. Environ. 2016, 222, 138-147.

4. Guisan, A.; Zimmermann, N.E. Predictive habitat distribution models in ecology. Ecol. Model. 2000, 135, 147-186.

5. Jiménez, L.; Soberón, J. Leaving the area under the receiving operating characteristic curve behind: An evaluation method for species distribution modelling applications based on presence-only data. Methods Ecol. Evol. 2020, 1-16, doi:10.1111/2041-210X.13479.

6. Nentwig, W.; Blick, T.; Bosmans, R.; Gloor, D.; Hänggi, A.; Kropf, C. Spiders of Europe. Version 11.2020. 2020, doi:10.24436/1. Available online: https://www.araneae.nmbe.ch (accessedon 20 October 2020).

7. Benhadi-Marín, J. (Centro de Investigação de Montanha, Bragança, Portugal); Pereira, J.A. (Centro de Investigação de Montanha, Bragança, Portugal). Personal observation, 2020.

8. R Core Team. R: A Language and Environment for Statistical Computing; R Foundation for Statistical Computing: Vienna, Austria, 2019. Available online: http://www.R-project.org (accessed on 20 October 2020).

9. Phillips, S.J.; Anderson, R.P.; Schapire, R.E. Maximum entropy modeling of species geographic distributions. Ecol. Model. 2006, 190, 231-259.

10. Hijmans, R.J.; Phillips, S.; Leathwick, J.; Elith, J. dismo: Species distribution Modeling. R package, version 1.1-4. 2017. Available online: https://CRAN.R-project.org/package=dismo (accessed on 7 September 2020).

11. Fick, S.E.; Hijmans, R.J. WorldClim 2: New $1 \mathrm{~km}$ spatial resolution climate surfaces for global land areas. Int. J. Climatol. 2017, 37, 4302-4315.

12. Feng, X.; Park, D.S.; Liang, Y.; Pandey, R.; Papeş, M. Collinearity in ecological niche modeling: Confusions and challenges. Ecol. Evol. 2019, 9, 10365-10376.

13. Muscarella, R.; Galante, P.J.; Soley-Guardia, M.; Boria, R.A.; Kass, J.M.; Uriarte, M.; Anderson, R.P. ENMeval: An R package for conducting spatially independent evaluations and estimating optimal model complexity for Maxent ecological niche models. Methods Ecol. Evol. 2014, 5, 1198-1205.

14. Merow, C.; Smith, M.J.; Silander, J.A. A practical guide toMaxent for modeling species' distributions: What it does, and why inputs and settings matter. Ecography 2013, 36, 1058-1069.

15. GBIF. The Global Biodiversity Information Facility. What is GBIF? 2020. Available online: https://www.gbif.org/what-is-gbif (accessed on 1 November 2020).

16. GBIF.org. GBIF Occurrence. 2020. Available online: https://doi.org/10.15468/dl.e3g5nm (accessed on 7 September 2020).

17. Caudullo, G.; Welk, E.; San-Miguel-Ayanz, J. Chorological maps for the main European woody species. Data Brief 2017, 12, 662-666. 
18. Fereres, E. Variability in adaptive mechanisms to water deficits in annual and perennial crop plants. Bulletin de la Société Botanique de France. Actualités Botaniques 1984, 131, 17-32.

Publisher's Note: MDPI stays neutral with regard to jurisdictional claims in published maps and institutional affiliations.

(C) 2020 by the authors; licensee MDPI, Basel, Switzerland. This article is an open access article distributed under the terms and conditions of the Creative Commons by Attribution (CC-BY) license (http://creativecommons.org/licenses/by/4.0/) 